\title{
Stability of a Cisplatin-Chondroitin Sulfate A Complex in Plasma and Kidney in Terms of Protein Binding
}

\author{
Jing-Shi Zhang, Shen-Feng Ma, Ayaka Suenaga, and Masaki Otagiri* \\ Faculty of Pharmaceutical Science, Kumamoto University, 5-1 Oe-honmachi, Kumamoto 862-0973, Japan. \\ Received January 9, 2001, accepted April 12, 2001
}

\begin{abstract}
To assess the stability of a cisplatin (CDDP) complex prepared with chondroitin sulfate A (CSA) relative to protein binding in the circulation and kidney, a trichloroacetic acid (TCA) precipitation method was developed to measure the protein-unbound species of CDDP and the CDDP-CSA complex in plasma and kidney homogenates. The total and unbound drug concentrations were determined up to $3 \mathrm{~h}$ following a $2 \mathrm{mg} / \mathrm{kg}$ bolus injection of CDDP or CDDP-CSA complex to rats. The stability against plasma binding was evaluated by a determination of the area under concentration-time curve from time 0 to infinite time $\left(A U C_{(0-\infty)}\right)$; the ratio of unbound drug $A U C_{(0-\infty)}$ to total drug $A U C_{(0-\infty)}$ was employed to estimate the availability of the unbound drug in the circulation. The results showed that a competitive reaction to platinum existed between plasma protein and the CDDP-CSA complex, but the complex accounted for more than $60 \%$ of the protein-unbound species for a dosage, compared to $30 \%$ obtained by an administration of uncomplexed CDDP. The tissue binding kinetics in kidney for CDDP and the CDDP-CSA complex was investigated by the use of homogenates. The binding rate constants of CDDP and CDDP-CSA in a kidney homogenate were $0.0040 \mathrm{~min}^{-1}$ and $0.0014 \mathrm{~min}^{-1}$, respectively. The results indicate that the CDDP-CSA complex could effectively retard the binding of CDDP to protein in the kidney. These data provide evidence that endogenous protein is able to compete for platinum from the CDDPCSA complex, but the complex effectively retarded the protein binding reaction with CDDP in plasma and kidney as compared to native CDDP, which has the potential for reducing the accumulation of CDDP in plasma and kidney.
\end{abstract}

Key words cisplatin; chondroitin sulfate A; complex; unbound drug; homogenate

In spite of the successful application of cisplatin (CDDP) as a chemotherapy agent, alone or in combination against several solid tumors, ${ }^{1,2}$ it would be desirable to modify it by synthetic chemical or pharmaceutical formulation methods, in order to overcome some of its side effects, especially its nephrotoxicity. ${ }^{3)}$ In order to reduce the nephrotoxicity, which is associated with CDDP treatment, we developed a CDDP complex using chondroitin sulfate A (CSA), a polycarboxyl polysaccharide. The CDDP-CSA complex had the same activity as the parent drug but showed reduced nephrotoxicity at high doses of CDDP. ${ }^{4}$ Thus, the results suggest that CDDP-CSA might reversibly release the active parent drug, due to reversible binding with the carboxyl group of the CSA, as observed with other carbohydrate compounds. ${ }^{5)}$ Therefore, it is important to examine the stability of the CDDP-CSA complex in the circulation, since plasma proteins may potentially compete for CDDP to form irreversibly bound species. Approximately $90 \%$ of the platinum in the blood exists in a protein-bound form following intravenous administration of CDDP. ${ }^{6,7)}$

Based on the above objective, we compared the plasma levels of total and protein-free platinum for both CDDP and the CDDP-CSA complex following intravenous administration. The availability of protein-free platinum in the circulation was used to evaluate the stability toward the protein binding. Moreover, the stability of the complex in the kidney was examined by incubation with a kidney homogenate.

\section{MATERIALS AND METHODS}

Chemicals and Animals CDDP was purchased from Sigma Chemical Company (St. Louis, MO, U.S.A.). Chondroitin sulfate A (CSA) with a mean molecular weight of
$23 \mathrm{KDa}$ was obtained from Seikagaku Corporation (Kanagawa, Japan). A CDDP-CSA complex was prepared by dissolving CDDP $(1 \mathrm{mg} / \mathrm{ml})$ and CSA $(8.4 \mathrm{mg} / \mathrm{ml})$ in deionized water, followed by shaking for $2 \mathrm{~d}$ until a reaction equilibrium of $80-85 \%$ of the CDDP forming a complex with the CSA had been reached. All other chemicals were of analytical grade. 7-week-old male Wistar rats $(230-250 \mathrm{~g})$ were used in the experiments.

Measurement of Total and Unbound Platinum Plasma Disposition Cannulations were performed on rats via the femoral vein and artery using polyethylene tubing (PE50) as described previously. ${ }^{4}$ CDDP was dissolved in saline at a concentration of $1 \mathrm{mg} / \mathrm{ml}$; the prepared complex (containing $1 \mathrm{mg} / \mathrm{ml}$ of CDDP) was made iso-osmotic by the addition of glucose. The freshly prepared solution, CDDP or CDDPCSA was then administered at a dose of $2 \mathrm{mg} / \mathrm{kg}$ via the formal vein. Blood samples $(0.3-0.4 \mathrm{ml})$ were collected from the femoral artery at $2,5,10,30,60,90,120$, and $180 \mathrm{~min}$ into heparinized microtubes, followed by rapid centrifugation, in order to isolate the plasma immediately. Following this procedure, $0.2 \mathrm{ml}$ of plasma was added to an equal volume of a cold mixture of $10 \% \mathrm{TCA}$ and $5 \% \mathrm{HCl}$, and the supernatant was analyzed for TCA-soluble platinum which represents the sum of the free and reversibly bound species. ${ }^{8)}$ The remaining plasma samples were used to determine the total platinum.

Measurement of Protein Binding in Kidney Rats, anesthetized with ether, were sacrificed, and the kidneys removed after perfusion with a cold homogenizing buffer through the renal artery to remove all blood. $1.6 \mathrm{~g}$ of kidney tissue including the cortex and outer medulla was dissected and homogenized in $5 \mathrm{ml}$ of $10 \mathrm{~mm}$ phosphate buffer containing $0.15 \mathrm{M} \mathrm{KCl}(\mathrm{PH} 7.4)$ at $1000-1200 \mathrm{rpm}$. CDDP or the 
CDDP-CSA complex was incubated with the homogenate at $37^{\circ} \mathrm{C}$. Aliquots $(0.2 \mathrm{ml})$ of homogenate were removed at 0 , $0.5,2,3,4$ and $6 \mathrm{~h}$, and added to an equal volume of cold mixture which contained $10 \% \mathrm{TCA}$ and $5 \% \mathrm{HCl}$. The supernatant was analyzed for TCA-soluble platinum.

Sample Analysis The platinum in the samples was detected using a flameless atomic absorption spectrophotometer, as described by Imai et al. ${ }^{9)}$ Briefly, plasma samples for the detection of total platinum were diluted 200-fold with $0.25 \%$ Triton X-100. The supernatant, used for the detection of unbound platinum, was diluted 100-fold with deionized water.

Data Analysis Statistical analyses were performed using Microsoft Statview 4.02 on a Macintosh platform, and evaluated for statistically significant differences by a one-way analysis of variance (ANOVA).

\section{RESULTS}

Stability against Plasma Protein Binding Total and protein-free drugs were detected in rats following a $2 \mathrm{mg} / \mathrm{kg}$ i.v. administration of CDDP or CDDP-CSA (Fig. 1). The concentrations of total and protein-free drug at $2 \mathrm{~min}$ after administration of the complex were $36.0 \pm 4.3 \mu \mathrm{g} / \mathrm{ml}$ and $35.6 \pm 4.4 \mu \mathrm{g} / \mathrm{ml}$, respectively, compared to $7.9 \pm 0.79 \mu \mathrm{g} / \mathrm{ml}$ and $7.5 \pm 0.71 \mu \mathrm{g} / \mathrm{ml}$ for CDDP treatment alone. The increased concentrations can be attributed to the suppression of distribution by the complex with a large molecular size. Moreover, in the case of i.v. administration of CDDP, the levels of protein-free platinum decreased rapidly with time, resulting in a significant difference in concentration between free and total drug observed after $30 \mathrm{~min}$. After $90 \mathrm{~min}$, the platinum species in circulation were mainly in the form of protein-bound platinum. In comparison, a significantly lower level of free drug than the total was found after $90 \mathrm{~min}$ in the case of the administration of the CDDP-CSA complex. This indicates that a competitive reaction to platinum actually exists between plasma protein and CDDP-CSA complex in the circulation; however, the complex effectively retards the protein binding reaction of platinum. The percent availability of protein-free drug per dosage was estimated from the area under the concentration-time curve $(A U C)$ from time 0 to infinite time, calculated by the linear trapezoidal method. The equation is expressed as follows:

availability $\%$ of free drug $=$

$$
100 \% \times A U C_{0 — \infty} \text { (free drug) } / A U C_{0 — \infty} \text { (total drug) }
$$

From the results listed in Table 1, it can be seen that only about $30 \%$ of the CDDP is available as free drug per dosage, and that the majority of the platinum is irreversibly bound to plasma protein. On the other hand, over $60 \%$ of the administered CDDP-CSA complex was available. It can be concluded that CDDP-CSA is stable in the circulation, to some extent, and significantly inhibits the binding of CDDP with plasma protein.

Stability against Protein Binding in the Kidney The protein-free platinum in the homogenate of the kidney was examined by precipitation with a solution that contained $10 \%$ TCA and $5 \% \mathrm{HCl}$. The logarithm plot of the detected free drug $v s$. time is linear, thus, the protein binding reaction of CDDP or CDDP-CSA in the homogenate followed apparent first-order behavior, and the binding rate constant can be estimated from the slope of the lines (Fig. 2). The protein binding rate constants of CDDP and CDDP-CSA are shown in Table 2. The results indicate that CDDP-CSA decreased the reaction rate of CDDP by a factor of 2.6, suggesting that the

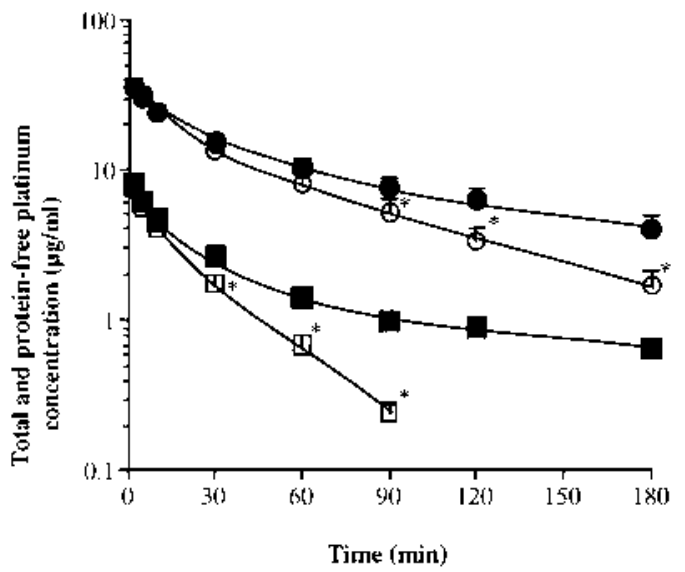

Fig. 1. Total and Protein-free Drug Levels of $\operatorname{CDDP}(\boldsymbol{\square}, \square)$ and CDDP-CSA-23 $(\bullet, \bigcirc)$ Following a $2 \mathrm{mg} / \mathrm{kg}$ Bolus I.V. Administration to Rats

All values are means \pm S.D. $(n=5)$. All points obtained for the total concentration of CDDP-CSA complex treatment are significantly greater than those of CDDP $(p<$ $0.05)$ ). * Significantly different from the corresponding result for the total $(p<0.05)$.

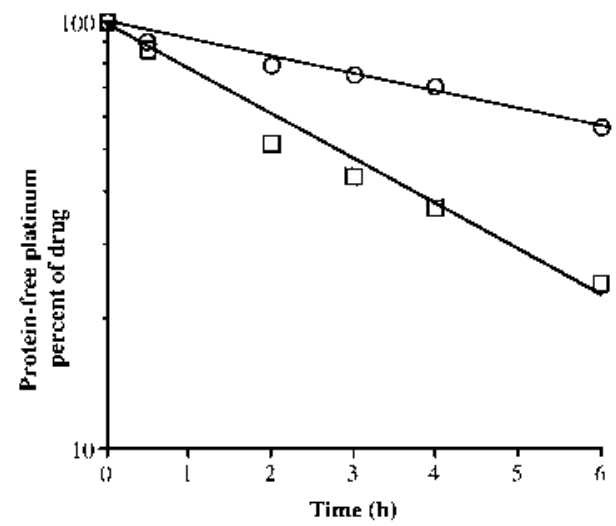

Fig. 2. Percentage of Unbound Initial Drug Concentration of CDDP ( $\square$ ) and CDDP-CSA Complex $(O)$ in a Kidney Homogenate as a Function of Incubation Time

Table 1. \% Availability of Protein-free Drug Following the Administration of CDDP or the CDDP-CSA Complex

\begin{tabular}{lccc}
\hline \hline Administration & $\begin{array}{c}A U C_{0-\infty}(\mu \mathrm{gh} / \mathrm{ml}) \\
\text { (total platinum) }\end{array}$ & $\begin{array}{c}A U C_{0-\infty}(\mu \mathrm{gh} / \mathrm{ml}) \\
\text { (protein-free } \\
\text { platinum) }\end{array}$ & $\begin{array}{c}\text { Availability (\%) of } \\
\text { protein-free drug }\end{array}$ \\
\hline CDDP & $7.63 \pm 2.0$ & $2.8 \pm 0.3$ & $34.7 \pm 3.6$ \\
CDDP-CSA complex & $38.1 \pm 4.9$ & $25.9 \pm 4.0$ & $68.3 \pm 4.2$
\end{tabular}

Table 2. Binding Rate Constants for CDDP and the CDDP-CSA Complex to Protein in Kidney

\begin{tabular}{lc}
\hline \hline Incubation & $K_{\text {app }}\left(\mathrm{min}^{-1}\right)$ \\
\hline CDDP & $0.0040 \pm 0.0008$ \\
CDDP-CSA complex & $0.0014 \pm 0.0002$ \\
\hline
\end{tabular}


CDDP-CSA complex effectively retarded the binding of platinum to kidney tissue proteins.

\section{DISCUSSION}

Detection of the protein-free platinum concentrations following administration of CDDP-CSA complex is essential for an evaluation of the stability of the linkage between drug and polymer, because plasma protein exerts a high affinity toward platinum. To measure protein-unbound platinum, three methods for the separation of protein are available, including plasma ultrafiltration, and precipitation by ethanol and trichloroacetic acid (TCA). ${ }^{10)}$ However, the choice for separating the protein from plasma which contains a CDDP-CSA complex became difficult due to the limitation of the enlarged molecular size for ultrafiltration and the co-precipitation of CSA with protein by ethanol. Therefore, protein precipitation using the TCA method was employed. We improved the recovery of the CDDP-CSA complex from plasma to nearly $100 \%$ by using a solution containing $10 \%$ TCA and $5 \% \mathrm{HCl}$, compared to an $80 \%$ recovery when $20 \%$ TCA was used alone. The results shown in Fig. 1 indicate that time-dependent changes in free CDDP-CSA in plasma following an i.v. administration were clearly obtained in the experiment. Furthermore, we applied this acid precipitation method to the detection of free drug in the kidney homogenate. The recovery of CDDP and CDDP-CSA complex was $94.3 \%$ and $96.1 \%$ on average, respectively.

The results obtained in the study indicate that a competitive reaction to platinum actually exists between plasma protein and the CDDP-CSA complex (Fig. 1). However, as compared to the treatment using CDDP, the administration of CDDP-CSA complex resulted in a marked elevation of protein-free drug in the circulation, which is due to both slower rates of disposition from the circulation of the macromolecular compound at an early time and stability against plasma protein binding. In addition, it was reported that only free CDDP was therapeutically effective and was available for excretion by glomerular filtration or by tubular secretion; ${ }^{11}$ also, that the protein-bound species disappear from the circulation with an extended half-life which is close to that of the plasma protein turnover. ${ }^{12,13)}$ Therefore, it is important to determine the percentage of free drug which is present in the circulation following the administration of a dose. This is a critical factor in terms of the therapeutic effectiveness and accumulation of the drug in the body. Our study showed that only a small portion of the administered dose was available as a protein-free drug following i.v. administration of CDDP. On the other hand, our results indicated that the CDDP-CSA complex is effective in inhibiting the protein binding of plat- inum in the circulation, with more than $60 \%$ of the administered dose available as a protein-free species. This suggests that the complex should be of benefit to increase the therapeutic effect of CDDP, or to reduce the dose of drug if it is necessary, as well as reduce the long term accumulation of platinum in the body.

Furthermore, it was reported that platinum binds to tissue protein in the kidney with the highest protein-binding rate as compared to other tissues, ${ }^{12}$ the kidney accumulated a considerable concentration of CDDP, which was eliminated from the kidney with a longer half-life than for other tissues. ${ }^{14,15)}$ The selective accumulation and retention of CDDP in the kidney is regarded as the most critical aspect of its nephrotoxicity. Therefore, we examined the stability of the complex against the tissue protein binding by use of a kidney homogenate, which is a simple method for the study of drug binding. ${ }^{16)}$ The results indicate that the complex can be stable in the homogenates of kidney, and retard the irreversible protein binding of platinum. The reduced affinity to the kidney of the complex should be one of the factors for reducing the accumulation of platinum in the kidney.

Based on this study, we can conclude that the CDDP-CSA complex is stable against protein binding in the plasma and kidney and provides much more protein-free species as compared to native CDDP, which may contribute to the reduction of accumulation which is observed in normal tissues.

\section{REFERENCES}

1) Lebwohl D., Canetta R., Eur. J. Cancer, 34, 1522-1534 (1998).

2) Smith I. E., Talbot D. C., Br. J. Cancer, 65, 787-793 (1992).

3) Wong E., Giandomenico C. M., Chem. Rev., 99, 2451-2466 (1999).

4) Zhang J. S., Imai T., Otagiri M., Arch., Toxicol., 74, 300-307 (2000).

5) Ducan R., Dimitrijevic S., Evagorou E. G., S. T. P. Pharm. Sci., 6, 237-263 (1996).

6) Gullo J. J., Litterst C. L., Maguire P. J., Sikic B. I., Hoth D. F., Woolley P. V., Cancer Chemother. Pharmacol., 5, 21-26 (1980).

7) Bednarski P. J., J. Inorg. Biochem., 60, 1-19 (1995).

8) Siddik Z. H., Newell D. R., Boxall F. E., Harrap K. R., Biochem. Pharmacol., 36, 1925-1932 (1987).

9) Imai T., Fujii K., Shiraishi S., Otagiri M., J. Pharm. Sci., 86, 244-247 (1997).

10) Ma J., Stoter G., Verweij J., Schellens J. H. M., Cancer Chemother. Pharmacol., 38, 391-394 (1996).

11) Daley-Yates P. T., McBrien D. C. H., Biochem. Pharmacol., 13, 2243-2246 (1982).

12) Farris F. F., King F. G., Dedrick R. L., Litterst C. L., J. Pharmacokinet. Biopharm., 13, 13-39 (1985).

13) Laznickova A., Filipova M., Laznicek M., Drobnil J., Svoboda D., Kvetina J., Neoplasma, 34, 173-181 (1987).

14) Choie D. D., Campo A. A., Guarino A. M., Toxicol. Appl. Pharmacol., $\mathbf{5 5}, 245-252(1980)$.

15) Goldstein R. S., Mayor G. H., Life Sci., 32, 685-690 (1983).

16) Pacifici G. M., Viani A., Clin. Pharmacokinet., 23, $449-468$ (1992). 